\title{
Transurethral resection of a bladder leiomyoma: A case report
}

\author{
Goksel Hasan Goktug, MD; ${ }^{*}$ Ufuk Ozturk, MD; ${ }^{*}$ Nevzat Can Sener, MD; ${ }^{\dagger}$ Can Tuygun, MD; Hasan Bakirtas, \\ $M D ;{ }^{*}$ Abdurrahim Muhammet Imamoglu, MD*
}

"Diskapi Teaching and Research Hospital, Ankara, Turkey; ${ }^{\dagger}$ Ministry of Health, Numune Teaching and Research Hospital, Department of Urology, Adana, Turkey

Cite as: Can Urol Assoc J 2014;8(1-2):e1 11-3. http://dx.doi.org/10.5489/cuaj.1335

Published online February 12, 2014.

\section{Abstract}

Benign mesenchimal tumour of the human bladder is rare. Insulin potentiation therapy mimics malignant tumours both clinically and radiologically. We present a patient we treated with transurethral resection (TUR) only. A 27-year old male patient presented to our clinic with frequency, dysuria and recurrent urinary tract infections. Magnetic resonance (MRI) revealed an endovesical bladder mass of $7 \times 8 \mathrm{~cm}$. We performed TUR in the same session for both diagnosis and treatment. The diagnosis was endovesical leiomyoma. Six months to a year after the operation, the MRI did not reveal disease recurrence. Even though TUR is recommended for smaller and endovesical tumours, we believe larger intravesical tumours may also be managed by TUR.

\section{Introduction}

Benign mesenchymal tumour of the human bladder is rare. ${ }^{1,2}$ The most common ones in this category are leiomyomas. They tend to be $30 \%$ extravesical, $7 \%$ intramural and $63 \%$ endovesical..$^{3-5}$ Leiomyomas are mostly asymptomatic. They may also accompany obstructive symptoms (49\%), irritative symptoms (38\%) or hematuria (11\%). Cystoscopy, ultrasound, tomography or magnetic resonance imaging (MRI) can be used in the diagnosis, but the definitive diagnosis is made by histopathology. There is not a single case of malignant transformation in bladder leiomyomas. ${ }^{6-9}$ The traditional treatment for symptomatic cases is surgical resection. The most important determinants for the choice of surgery are tumour size, localization and its involvement of urinary sphincter or ureter orifices. ${ }^{10}$ We present a patient we treated with transurethral resection (TUR) only.

A 27-year old male presented to our clinic with frequency, dysuria and recurrent urinary tract infections. His fam- ily history and physical examination were unremarkable. Abdominal ultrasound revealed a mass in the left wall of the bladder, but no hydronephrosis. A magnetic resonance image revealed an endovesical bladder mass of $7 \times 8 \mathrm{~cm}$ (Fig. 1). A cystoscopy was performed. It revealed a mass invading both left and anterior bladder walls, but not involving orifices. The bladder epithelium was normal over the mass. Due to the tumour's proximity to the orifice and the patient's preference, we performed TUR in the same session for both diagnosis and treatment. The pathology revealed fusiform smooth muscle cells with fusiform nuclei in hyalinised stroma; the diagnosis was endovesical leiomyoma (Fig. 2). The patient was discharged the day after the operation and MRI did not reveal any recurrences 6 months and 1 year after the surgery.

\section{Discussion}

Even though leiomyomas tend to appear in the urinary tract, the most common site is the renal capsule. ${ }^{11}$ Benign tumours invading the bladder are myoma, leiomyoma, rhabdomyoma, fibroma, angioma, osteoma and mixoma. The most common benign mesenchymal bladder tumour is leiomyoma. The first bladder leiomyoma was reported in $1931,{ }^{12}$ and after that about 250 cases have been reported. ${ }^{13}$ Most of the masses were smaller than $10 \mathrm{~cm}$, but the lengths ranged from millimeters to $30 \mathrm{~cm} .^{7,14-16}$ It is proposed that women in their third, fourth, fifth and sixth decade of life most commonly encounter leiomyomas, ${ }^{14}$ most likely due to the use of pelvic ultrasound with this wide age group. ${ }^{8}$ The youngest patient ever reported was a 4 -year-old girl. ${ }^{17}$

There are many proposed etiologies for leiomyoma, including chromosomal anomalies, hormonal changes, infection of bladder smooth muscle, perivascular inflammations and disonthogenesis. ${ }^{14}$

Bladder leiomyomas are generated from subephitelial smooth muscle; they tend to be $30 \%$ extravesical, $7 \%$ 


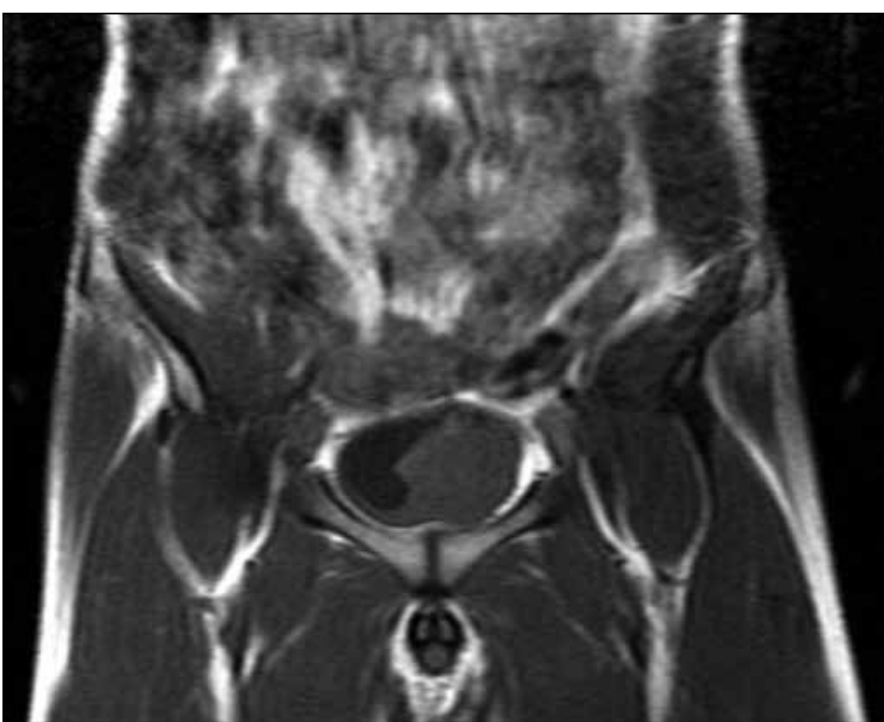

Fig. 1. The magnetic resonance image of the patient with bladder leiomyoma.

intramural and $63 \%$ endovesical..$^{3-5}$ Symptoms appear as alterations of the tumour size and location. ${ }^{18}$ The most symptomatic type is endovesical leiomyoma. Symptoms are obstructive $(49 \%)$, irritative $(38 \%)$ or hematuria $(11 \%) ., 14,19,20$ Our patient had an endovesical leiomyoma and irritative symptoms.

In a case group of 61 patients, $37.7 \%$ had irritative symptoms, $31.1 \%$ had obstructive symptoms, $24.6 \%$ had hematuria, $14.8 \%$ had abdominal mass or pain and $27.9 \%$ were asymptomatic. ${ }^{18}$ Surgery may be delayed for asymptomatic patients. ${ }^{21}$ For symptomatic patients, the aim must be to relieve symptoms, because malign transformation has not been reported..$^{6-9,16}$

Several treatments have been described. TUR or fulguration is recommended for small, endovesical tumours, whereas for bigger, endovesical, intramural or extravesical tumours, segmental resection is recommended. ${ }^{16,21}$ TUR, segmental resection or partial cystectomy is successfully performed in an open, laparoscopic or robotic fashion. . $^{8,22,23}$

Because of the tumour's proximity to the orifice and the patient's preference, we performed TUR in the same session for both diagnosis and treatment. TUR was the patient's choice because of its relative non-invasiveness. ${ }^{24,25}$ After TUR, we did not perform additional treatments, but we followed up the patient closely. In 6 months, follow-up ultrasound was normal. Cystoscopy was performed and the inspection and random biopsies did not reveal any recurrence.

\section{Conclusion}

Even though TUR is recommended for smaller and endovesical tumours, we believe larger intravesical tumours may also be managed by TUR.

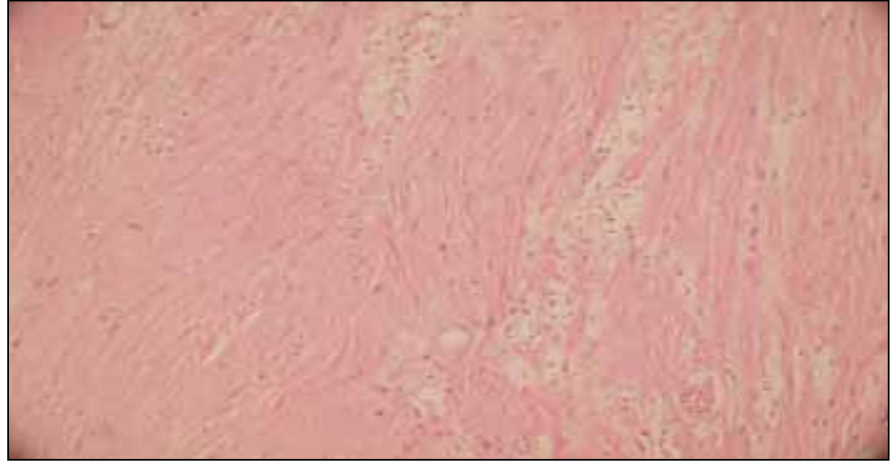

Fig. 2. The pathological image of the bladder leiomyoma.

Competıng interests: Dr. Goktug, Dr. Ozturk, Dr. Sener, Dr. Tuygun, Dr. Bakirtas, Dr. Imamoglu all declare no competing financial or personal interests.

This paper has been peer-reviewed.

\section{References}

1. Soloway D, Simon MA, Milikowski C, et al. Epithelioid leiomyoma of the bladder: An unusual cause of voiding symptoms. Urology 1998:51:1037-9. http://dx.doi.org/10.1016/S0090-4295(98)00016-8

2. Bai SW, Jung HJ, Jeon MJ, et al. Leiomyomas of the female urethra and bladder: A report of five cases and review of the literature. Int Urogynecol J Pelvic Floor Dysfunct 2007;18:913-7. http://dx.doi. $\operatorname{org} / 10.1007 / \mathrm{s} 00192-006-0257-9$

3. Campbell EW, Gislason GJ. Benign mesothelial tumors of the urinary bladder: Review of literature. J Urol 1953;70:733-41.

4. Deliveliotis C, Giannakopoulos S, Zougri S, et al. Leiomyoma of the bladder: A case report. Int Urol Nephrol 1998;30:141-3. http://dx.doi.org/10.1007/BF02550568

5. Fernandez A, Mayayo DT. Leiomyoma of the urinary bladder floor: Diagnosis by transvaginal ultrasound. Urol Int 1992;48:99-101. http://dx.doi.org/10.1159/000282305

6. Menahern MM, Chryystia S. Urinary bladder leiomyoma resonance imaging findings. Urol Radiol 1992;14:197-9. http://dx.doi.org/10.1007/BF02926929

7. Kim IY, Sadeghi F, Slawin KM. Dyspareunia: An unusual presentation of leiomyoma of the bladder. Rev Urol 2001;3:152-4

8. Cornella JL, Larson TR, Lee RA, et al. Leiomyoma of the female urethra and bladder: report of twentythree patients and review of the literature. Am J Obstet Gynecol 1997;176:1278-85. http://dx.doi. org/10.1016/50002-9378(97)70346-6

9. Bai SW, Jung HJ, Jeon MJ, et al. Leiomyoma of the female urethra and bladder: a report of five cases and review of the literature. Int Urogynecol J Pelvic Floor Dysfunct 2007;18:913-7. http://dx.doi. org/10.1007/s00192-006-0257-9

10. Park JW, Jeong BC, Seo SI, et al. Leiomyoma of the urinary bladder: A series of nine cases and review of the literature. Urology 2010;76:1425-9. http://dx.doi.org/10.1016/i.urology.2010.02.046

11. Zuckerman IC, Kershner D, Laytner BD, et al. Leiomyoma of the kidney. Ann Surg 1947;126:220-8. http://dx.doi.org/10.1097/00000658-194708000-00008

12. Kretschmer JL. Leiomyoma of the bladder with a report of a case and a review of the literature. J Urol 1931;26:575-89.

13. Saunders SE, Conjeski IM, Zaslau $S$, et al. Leiomyoma of the urinary bladder presenting as urinary retention in the female. Can I Urol 2009;16:4762-4.

14. Goluboff ET, O'Toole K, Sawczuk IS. Leiomyoma of the bladder: report of case and review of literature. Urology 1994;43:238-41. http://dx.doi.org/10.1016/0090-4295(94)90053-1

15. Knoll LD, Segura JW, Scheithaver BW. Leiomyoma of the bladder. J Urol 1986;136:906-8.

16. Broessner C, Klingler CH, Bayer G, et al. A 3,500-gram leiomyoma of the bladder: case report on a 3-year follow-up after surgical enucleation. Urol Int 1998;61:175-7. http://dx.doi.org/10.1159/000030317

17. Büyükkalpelli R, Aybek Z, Yildı S, et al. Mesane leiomyomu: 4 ya inda bir olgu sunumu. Üroloji bülteni 1992;3:229.

18. Jiang $X Z$, $X \cup C$, Zhang NZ, et al. Influence of clinical characteristics and tumor size on symptoms of bladder leiomyoma: A pooled analysis of 61 cases. Chin Med J (Engl) 2012;125:2436-9. 
19. Lin HC, Wu HJ, Ke HL, et al. Bladder leiomyoma presenting as voiding dysfunction: A case report. Kaohsiung J Med Sci 2006;22:154-7. htrp://dx.doi.org/10.1016/S1607-551X(09)70236-0

20. Elshebiny YH, Ashebu HM, Hussein SD, et al. Leiomyoma of the urinary bladder: Case report. East Afr Med J 2002;79:557-9. http://dx.doi.org/10.4314/eami.v79i10.8822

21. Yi KI, Sadeghi Slawin KM. Dyspareunia: An unusual presentation of leiomyoma of the bladder. Rev Urol 2001;3:152-4

22. Jeschke K, Wakonig J, Winzely M, et al. Laparoscopic partial cystectomy for leiomyoma of the bladder wall. J Urol 2002;168:2115-6. http://dx.doi.org/10.1016/S0022-5347(05)64309-1

23. Lake MH, Kossow AS, Bokinsky G. Leiomyoma of the bladder and urethra. J Urol 1981;125:742-3.
24. John Nk, Fuad SF, James DN. Leiomyoma of bladder: report of 2 cases and demonstration of ultrasonic appearance. Urology 1990;45:210-2.

25. Ninan AC, St Luce S, Kimberl IJ, et al. Endoscopic enucleation of leiomyoma of the bladder. Urol Int 2005;75:8-9. http://dx.doi.org/10.1159/000085919

Correspondence: Dr. Nevzat Can Sener, Ministry of Health, Ankara Dışkapı Yıldıım Beyazit Education and Research Hospital, Department of Urology, Ankara, Turkey; cansener14@gmail.com 